\title{
TENSÕES CURRICULARES E NARRATIVAS: o ensino de História da América Latina
}

\author{
Raquel Alvarenga Sena Venera* \\ Juliana Pirola da Conceição**
}

\section{Resumo}

Este trabalho versa sobre parte das análises resultantes da pesquisa intitulada "A Escola e os jovens no mundo contemporâneo: processos de formação histórica latino americana” desenvolvida em duas escolas na cidade de Florianópolis, de 2009 a 2011. Essas escolas são públicas e campos de estágio de formação inicial de professores de História da Universidade Federal de Santa Catarina. A pesquisa empírica foi desenvolvida junto aos jovens da sétima série do Ensino Fundamental e investigou a formação da consciência histórica latino americana. Para esse artigo, especificamente, o foco é a relação entre as escolhas curriculares para o Ensino de História, das duas escolas e a inferência delas nas narrativas dos estudantes acerca da História latino americana. Busca-se uma leitura conceitual de currículo, a partir dos Estudos Culturais, que permite a percepção de tensões políticas na construção de pertencimentos e identidades dos jovens e que foram expressas em suas narrativas sobre a América Latina. As análises aqui apresentadas dão visibilidade às disputas na construção de memórias e identidades, no interior do currículo, que atuam na orientação da vida presente dos jovens e na construção de perspectivas de futuros. Neste movimento são realizadas escolhas que mobilizam determinados saberes de acordo com os sujeitos que se deseja formar e as identidades que se pretende construir.

Palavras-chave: Educação. Políticas públicas. Currículo. Formação histórica. Juventudes.

\section{HISTORY TEACHING: curricular policies, school culture, knowledge and teaching practices}

\footnotetext{
Abstract

This paper runs upon the analyses of the research entitled "The school and the youth in the contemporary world: processes of Latin American historic formation” developed in two schools in the city of Florianópolis from 2009 to 2011. These public schools are the training field of initial formation of History teachers in the Federal University of Santa Catarina. The empiric research was developed with the youngsters of the seventh grade of Elementary School and investigated the building of the Latin American historic consciousness. This article focuses on the relation between the curricular choices for the History Teaching of both schools, and their

* Doutora em Educação pela Universidade Estadual de Campinas. Professora da Universidade da Região de Joinville. E-mail: raquel.venera@univille.br

** Doutoranda em Educação pela Universidade Estadual de Campinas. E-mail: jupirola@hotmail.com
} 
inference in the students' narratives about the Latin American History. A conceptual reading of the curriculum is tempted, through the Cultural Studies that allows the perception of political tensions in the construction of a belonging feeling and the youth identities that were presented in their narratives about the Latin America. The analyses presented bring the fights for the memories and identities to surface, inside the curriculum, which guide the youngsters' life and their future perspective building. In this movement, choices that are made determine the knowledge according to the subjects and identities that are wished to be built.

Keywords: Education. Public policy. Curriculum. Historic formation. Youth.

\section{Uma introdução necessária}

Este artigo trata das práticas curriculares desenvolvidas para o Ensino de História em sua relação com a produção de narrativas históricas produzidas por jovens estudantes, num movimento dinâmico de representação e interpretação de experiências, do tempo, de si mesmo e da própria História. O escopo do trabalho está nas práticas de seleção e organização do conhecimento histórico em contexto escolar, que implicam na difusão e consolidação de ideias, imagens e saberes associados a uma educação política e abrem possibilidades para a construção e consolidação de memórias e identidades, como um sentimento de pertencimento em um mundo em transformação.

Trata-se de uma reflexão sobre os resultados obtidos na pesquisa intitulada "A Escola e os jovens no mundo contemporâneo: processos de formação histórica latino-americana" 1 , desenvolvida pelo Núcleo Interdisciplinar de Pesquisas em Ensino de História (NIPEH), da Universidade Federal de Santa Catarina (UFSC), nos anos de 2009 a 2011. Essa pesquisa investigou o ensino dos conhecimentos históricos relacionados à América Latina na mediação realizada pelas disciplinas escolares e pelos artefatos culturais da cultura contemporânea, como filmes, programas televisivos, leituras, músicas, revistas, internet e outros, manifestos no vocabulário e no comportamento dos jovens dentro e fora das salas de aulas de História. Em particular, desejou-se compreender qual a contribuição dos conteúdos latino-americanos no currículo para a formação histórica dos jovens na escola.

A pesquisa empírica foi realizada em 2009/2010 e teve como recorte de investigação as duas escolas que serviram de campos de estágio para a formação de professores de História da UFSC naqueles anos: o Colégio de Aplicação (CA) da Universidade Federal de Santa Catarina (UFSC), e a Escola Estadual Básica Dom Jaime de Barros Câmara (DJ).

\footnotetext{
${ }^{1}$ A pesquisa foi coordenada pela Dra. Maria de Fátima Sabino Dias, contou com financiamento externo da FAPESC e com pesquisadoras da UFSC, UNIVALI e UNIVILLE. O projeto estava vinculado a pesquisa interinstitucional intitulado “Peabiru: Ensino de História e Cultura Contemporânea”, financiado pelo CNPq, que agrega pesquisadores de seis universidades brasileiras e uma argentina sob a coordenação da Dra. Ernesta Zamboni, do Grupo Memória da UNICAMP.
} 
O CA está situado no campus da UFSC, na região central de Florianópolis, e se apresenta como uma escola experimental, mantida pela Universidade e integrada ao Sistema Federal de Ensino. Além disso, o CA oferece no seu currículo uma disciplina inédita no país para tratar especificamente da temática latino-ameicana: a disciplina de Estudos Latinoamericanos (ELA), implementada em 2003 por iniciativa dos próprios professores em substituição à disciplina de Organização Social e Política do Brasil (OSPB). A disciplina está alocada no currículo de História do CA e integra o currículo da $7^{\mathrm{a}}$ série do Ensino Fundamental e do $1^{\circ}$ ano do Ensino Médio, contando com uma carga horária anual de 75 aulas.

O DJ está situado no extremo sul da ilha de Florianópolis e integra o Sistema Estadual de Ensino. Nesta escola a temática latino-americana está presente nos livros didáticos utilizados e em projetos pontuais de alguns professores, sem uma intencionalidade específica para o seu ensino.

A amostragem selecionada para a pesquisa privilegiou os jovens estudantes das $7^{\text {a }}$ séries, nas duas escolas. Ao total, 112 jovens participaram da pesquisa, sendo 67 do CA e 45 do DJ. Eles responderam a um questionário do tipo survey ${ }^{2}$ composto por 42 questões de múltipla escolha semi-abertas sobre sua situação social e econômica, suas principais ocupações, vida familiar, acesso à informação, consumo de mídias e interferência da disciplina cursada no aprendizado da história da América Latina. Em seguida, foi proposta a realização de uma tarefa escrita, individual, que estimulasse a imaginação histórica dos jovens para a produção de narrativas que interrelacionassem o passado, o presente e o futuro da América Latina, nas quais as experiências do tempo presente pudessem ser inseridas interpretativamente e exploradas em uma perspectiva de futuro.

O conteúdo das narrativas produzidas foi analisado a partir dos elementos mais freqüentes; das perspectivas de futuro e das representações que elas mobilizam sobre si e sobre a história da América Latina. Os dados referentes à formação da consciência histórica foram explorados no artigo "Ensino de História e consciência histórica latino-americana" (CONCEIÇÃO; DIAS, 2011). Para esse trabalho, especificamente, o foco está nas representações mobilizadas nos elementos mais frequentes das narrativas que dão pistas para um entendimento da relação entre as práticas curriculares das duas escolas envolvidas na

\footnotetext{
2 Os surveys, também conhecidos como “polling” em âmbito internacional, são pesquisas exploratórias utilizadas para produzir enunciados descritivos sobre alguma população e pontuar a distribuição de certos traços e atributos. Trata-se de um método de coleta de dados ou informações usadas para descrever, comparar ou explicar características, opiniões, conhecimentos, valores, atitudes etc., individualmente ou socialmente dentro de um grupo.
} 
pesquisa e a produção das tensões constitutivas da produção de identidades e memória. Os resultados obtidos colocaram em evidência a interferência das práticas curriculares desenvolvidas para o Ensino de História na produção de representações e interpretações não só da história latino-americana, mas também de si mesmo e da própria História.

As políticas públicas curriculares estavam disponíveis para as duas escolas. As condições de trabalho dos professores e a cultura escolar eram evidentemente diferenciadas, mas os resultados do Exame Nacional do Ensino Médio de 2010 revelaram o desempenho das duas escolas em um mesmo recorte de resultados - acima da média entre as demais escolas públicas do estado de Santa Catarina ${ }^{3}$.

Estava evidente que não se tratava de medir a competência dos professores a partir do que os jovens eram capazes de narrar, nem mesmo de defender um ou outro modelo curricular sem levar em conta sua forma e condições de produção. Os modelos distintos de currículos de História nas duas escolas possuem, no interior da sua distinção as suas condições de produção e de realização. Se por um lado vivemos um movimento de uniformização e padronização dos conteúdos ensinados nas escolas em virtude das avaliações nacionais, por outro lado, há que se destacar que o currículo é, em última instância, produzido e praticado pelo professor em seu trabalho cotidiano. Neste processo suas referências, opções políticas e condições de trabalho ocupam um papel de destaque na configuração do quê e como será ensinado.

Esta multiplicidade de fatores promove um movimento de plasticidade, de fluxos intercambiáveis no interior dos currículos, que ficaram evidentes nesta pesquisa. Duas escolas diferentes - redes estadual e federal de ensino -; professores diferentes - com formações, salários e carreiras diferenciadas -; culturas locais diferentes - uma no interior de um campus universitário e envolta de uma vida urbana intensa, e outra na periferia da cidade, no interior de uma comunidade conhecida como "tradicional”-; e políticas públicas parcialmente flexíveis, que permitiram ações docentes diferenciadas, resultados semelhantes no Enem e produções de sentidos distintos sobre a história da América Latina.

A questão que se desenvolveu nesse artigo foi, em que medida as escolhas explicitas nesses currículos para o Ensino de História, cada uma a sua maneira, se relacionam com as intencionalidades de construção de memória e identidade dos jovens estudantes e com as narrativas produzidas pelos jovens? Na expectativa de oferecer elementos que ajudem a

\footnotetext{
${ }^{3}$ Os resultados divulgados pelo veículo de comunicação Folha.com, possibilitou a visualização das médias das escolas em relação aos resultados no Estado e no Brasil e classificou estes resultados entre: Acima da média = acima de 554,06; Na média = de 520,01 a 554,06; Abaixo da média = a partir de 520,01. Disponível em: $<$ http://saber.folha.com.br/2010/enem/ranking?estado=SC>. Acesso em: 15 fev. 2012. Os resultados foram também divulgados pelo MEC, no entanto a acessibilidade em escala para o público em geral foi mais visível nos meios de comunicação. O CA atingiu média 611,42 e o DJ média 560,75.
} 
refletir sobre essa questão, o artigo está organizado da seguinte maneira: em um primeiro momento relacionaremos as tensões presentes nas práticas curriculares desenvolvidas para o Ensino de História, especialmente no que tange a construção de memórias coletivas e identidades. A seguir discutiremos as relações estabelecidas na pesquisa entre conhecimentos, sujeitos e suas narrativas sobre a América Latina. Esses dois blocos de discussão possuem o objetivo apenas organizativo do texto, pois estão interligados naquilo que chamamos de “reflexões sempre provisórias” sobre o ensino de História da América Latina.

\section{Tensões curriculares e arranjos da construção de memórias coletivas e identidades}

Tomando o currículo ao mesmo tempo, como política pública e como produto histórico do trabalho escolar, reconhecemos seu potencial na difusão sistemática de ideias, imagens e saberes associados a uma educação política, especialmente no Ensino de História, abrindo caminhos para a construção e consolidação de memórias e identidades, sejam elas nacionais, locais ou culturais.

Ao abordar esta questão é importante nos reportarmos historicamente à finalidade da História como disciplina escolar. Sabe-se que a instituição escolar estruturou, tradicionalmente, o ensino de História a partir da matriz nacionalista do século XIX, cujo objetivo era formar a identidade de, seja de "franceses”, "brasileiros” ou "chilenos" ou qualquer outra nacionalidade, para a nova sociedade que forjava os Estados nacionais. Apesar de todas as mudanças que a disciplina sofreu ao longo dos séculos, o ensino de História permanece como espaço de disputa na construção de memórias e formação de identidades, não mais necessariamente nacionalistas, mas quais identidades são privilegiadas?

Na contemporaneidade, marcada pelo esfacelamento das individualidades diante dos processos de globalização, a formação de identidades torna-se um dado emergente, pois o sentimento de pertencer a um lugar, a um grupo no qual se desempenha um papel social como envolvimento emocional e afetivo e com o qual nos identificamos é muito importante para reconhecer interesses comuns e projetar futuros coletivos (ZAMBONI, 2003).

No Brasil contemporâneo, não são raros os trabalhos que evidenciam a preocupação com a construção de um currículo mais inclusivo e comprometido com a construção de identidades no plural, abarcando diferentes etnias, classes sociais, religiões etc, que fortaleça a instituição escolar como formadora de cidadania. Esta premissa está evidente nas políticas públicas, nos documentos oficiais da educação - trata-se de políticas multiculturais que 
evocam um sentido de igualdade de direitos, mas, ao fazer isso, coloca em cena, também, a demanda dos direitos as diferenças.

As pesquisas sobre currículo apresentam evidencias de que ao ser construído ele carrega marcas, registros, traços das disputas por sentidos culturais hegemônicos. Estão no interior dos currículos as tensões para definições de identidades, de memórias e de culturas dos diferentes grupos sociais. Este entendimento leva a constatação, nas palavras de Tomaz Tadeu da Silva, de que “[...] nós somos o que nos tornamos, o que significa que podemos também nos tornar, agora e no futuro, outra coisa” (SILVA, 1999, p. 26). Estendendo esse raciocínio para as práticas curriculares, ainda nas palavras do mesmo autor, “[...] o currículo está centralmente envolvido naquilo que somos, naquilo que nos tornamos, naquilo que nos tornaremos. O currículo produz, o currículo nos produz” (SILVA, 1999, p. 27).

No movimento de constituição dos currículos oficiais e de elaboração das práticas curriculares cotidianas estão presentes tensões que revelam as disputas na construção de memórias e identidades que atuarão na orientação da vida presente e na construção de perspectivas de futuro. Neste movimento são realizadas escolhas na mobilização de determinados saberes, contextos ou personagens, de acordo com os sujeitos que se deseja formar e as identidades que se pretende construir.

No caso específico da América Latina, tal tensão remete à busca ou omissão de construção de identidades históricas com os países vizinhos. Este posicionamento, político em primeira instância, se traduz em opções curriculares, sejam elas oficiais ou nas práticas cotidianas, que implicam a seleção e organização dos conteúdos a serem ensinados e sua forma de circulação no ambiente escolar e fora dele.

Nos Parâmetros Curriculares Nacionais de História, PCNs, para as $5^{\mathrm{a}}$ e $8^{\mathrm{a}}$ séries do Ensino Fundamental encontram-se várias sugestões de temas para o estudo da história da América Latina, dentre elas: "Relações entre a sociedade, a cultura e a natureza na História dos povos americanos na Antiguidade e entre seus descendentes hoje”; "Relações de trabalho em diferentes momentos da História dos povos americanos, "Processos de constituição dos Estados Nacionais na América, confrontos, lutas, guerras, revoluções” (BRASIL, 1998. p. 58, 60 e 70). Da mesma forma é possível observar que muitas coleções de livros didáticos têm incluído em seus sumários algumas propostas de trabalho com temáticas latino-americanas. No entanto, a fragmentação dos conteúdos e a forma como muitas vezes essas temáticas são trabalhadas separadamente do estudo do contexto brasileiro, quando chegam a ser trabalhadas, não favorecem a aproximação com os países vizinhos pela exotização do “outro” latino- 
americano, em detrimento de uma visão integrada da história do continente em que prevaleçam as similitudes do seu processo histórico.

As duas escolas envolvidas nesta pesquisa, exercendo a autonomia e a liberdade de que dispõem na confecção de seus programas curriculares, colocam em evidência a dinâmica desse movimento de seleção e organização dos conteúdos, em sua relação direta com os sujeitos que desejam formar e as identidades que pretendem construir. Como já foi dito, em 2003 o CA instituiu em seu curriculo de ensino uma disciplina específica para tratar da temática latino-americana, a disciplina de ELA, por iniciativa dos próprios professores.

A proposta de inclusão da disciplina foi realizada a partir das possibilidades criadas pela Lei $\mathrm{n}^{\circ}$ 8.663, de 14 de junho de 1993, que extinguiu oficialmente as disciplinas de Organização Social e Política do Brasil (OSPB) e Educação Moral e Cívica (EMC) do currículo escolar brasileiro e abriu espaço para que a carga horária dessas disciplinas fosse preenchida por disciplinas da área das ciências humanas e sociais à critério dos estabelecimentos de ensino.

Pioneiro nessa proposta, o CA da UFSC utilizou este espaço para incluir em seu programa uma disciplina que não só propiciasse um direcionamento de olhar para o contexto latino-americano, como também abrisse a possibilidade para a construção de um sentimento de pertencimento do Brasil na América Latina. Entre os objetivos explicitados na proposta de inclusão da disciplina estão:

Propiciar a reflexão sobre as questões históricas, sociais e culturais da América numa perspectiva que problematize questões ligadas às identidades locais, nacionais e continentais, que discuta como essas questões se articularam aos diversos projetos políticos, as vicissitudes econômicas e as perspectivas históricas desses povos.

Objetivos específicos:

- Possibilitar o auto-conhecimento (sic) étnico-político a partir da problematização de questões recorrentes e inéditas na América Latina.

- Propiciar o contato entre cidadãos brasileiros, argentinos e outros, numa perspectiva de alteridade e solidariedade.

- Divulgar a história dos povos americanos, numa perspectiva comparativa, fazendo emergir o conhecimento significativo sobre as sociedades do continente, contrapondo-se a estereótipos e preconceitos (SOUZA e VERÍSSIMO, 2003. p. 12).

Como aponta Tomaz Tadeu da Silva, o currículo é "um empreendimento ético, em empreendimento político” (SILVA, 1999, p. 29). e no caso do CA revela o posicionamento político de seus professores em defesa da aproximação das culturas latino-americanas, uma disciplina vinculada explicitamente em uma aposta de um espaço de significações e construções de pertencimento social dos jovens estudantes à América Latina. No entanto, não 
se trata de negar as representações européias, tradicionais dos currículos brasileiros, trata-se fundamentalmente de colocar no jogo de disputa, também, os discursos sobre as identidades latino-americanas.

[...] porque esta inclusão ultrapassa as questões internas da cultura escolar, ela manifesta uma postura política perante o mundo globalizado que vivemos, a coerência com nosso discurso crítico ao eurocentrismo e favorável ao respeito às diferentes culturas e, especificamente, à nossa consciência de americanidade (SOUZA e VERÍSSIMO, 2003. p. 09).

Já no DJ, assim como na maioria das escolas brasileiras, o estudo da História do continente latino-americano de maneira integrada não aparece explicitamente como objetivo político ou pedagógico da escola, assim como também não é evidente a preocupação com a construção de identidades mais integradoras, que ultrapassem os limites da nacionalidade. Fica a critério dos professores, a partir de suas referências e posicionamentos políticos, a opção por priorizar, integrar ou omitir o ensino de conteúdos históricos relacionados à América Latina.

O planejamento do professor de História do DJ, no momento da realização da pesquisa, seguia a convenção do modelo quadripartite francês - História Antiga, Medieval, Moderna e Contemporânea -, em um esforço de constituir um tempo sincrônico que identifique as relações históricas de sociedades situadas em espaços diversos, com especial atenção ao espaço europeu. Apesar da intencionalidade política não aparecer explicitamente, seria ingênuo afirmar sua inexistência. Além da organização de conteúdos, existe algo funcionando neste currículo, nesta cultura escolar que a deixa muito próxima da comunidade local e esse fato é político e intencional. As atividades comunitárias são envolvidas pela escola e, nesses termos, ela toma partido ao lado dos discursos em defesa da tradição açoriana e católica, comuns na tradição local. As ações organizadas pela escola contam com a participação de líderes da comunidade e vice-versa, em uma demonstração política de compromisso do que aqueles adultos -professores, pais e líderes comunitários - entendem ser o melhor para construção identitária dos jovens. O Festival Literário da escola, por exemplo, torna um evento da comunidade, assim como a Festa do Divino Espírito Santo, da paróquia local, conta com uma participação especial dos professores e jovens, estudantes da escola, que por sua vez são, também, envolvidos com a banda e o grupo de teatro local.

Ambas as escolas tomam partido na construção identitária dos jovens que a frequentam. De maneira diferente e com metodologias distintas preocupam-se com uma universalidade contemporânea em que os jovens estão envolvidos que, ao massificar as 
supostas identidades, fazem sumir as diferenças que os identificariam - a descendência açoriana local e a possibilidade de pertencimento latino-americano. Essas diferenças são apresentadas aos jovens cada vez mais cedo, a partir da construção ou consolidação das memórias negociadas no contexto escolar. A universalidade, entendida como o simbólico de uma plenitude sempre ausente, e esse particular, que existe no movimento contraditório de afirmar uma identidade diferencial e cancelá-la mediante sua subordinação em um meio não diferencial. (LACLAU, 1995)

A criação da disciplina de ELA no CA possui intenções claras de construção de uma identidade latino-americana junto aos jovens. Caberia nessa análise sempre a pergunta formulada por Stuart Hall, “Quem precisa de identidade?” (HALL, 2000, p.103) Se, o currículo constrói identidades, e, se, também, ele massifica com seu discurso universal sobre os conhecimentos, ousaríamos dizer que os personagens inseridos em um currículo são grávidos de identidades. Estão no movimento tensional entre aparecer/desaparecer, ser visto/ser invisível, ser memorado/ser esquecido, ser universal/ser particular. Hall (2000) aproxima o conceito de identidade ao sentido de sutura que interpela o sujeito pela linguagem convocando-o para assumir seu lugar como sujeitos sociais - no caso do CA, como latinoamericanos e no caso DJ, como descendente de açorianos - e, ao mesmo tempo aquele discurso particular que o sujeito se investe, que possui relações com suas identificações, com suas faltas ou desejos. Todavia, estas também são construídas, mas contam com o investimento do sujeito. Nas palavras de Hall:

Se uma saturação eficaz do sujeito a uma posição-de-sujeito exige não apenas que o sujeito seja "convocado", mas que o sujeito invista naquela posição, então a suturação tem que ser pensada como uma articulação e não como um processo unilateral. (HALL, 2000, p. 112)

Desta forma, as narrativas analisadas nesta pesquisa foram entendidas como produtos desses investimentos de suturas discursivas. Por um lado, o ensino de conhecimentos relativos à História da América Latina, que são priorizados nos currículos tradicionais da História ensinada, numa evocação dos sujeitos a se reconhecerem como latinos no jogo entre o universal e o particular. Por outro lado, a espera por um investimento por parte dos jovens para se identificarem e se posicionarem, mesmo que de forma temporária, a essas práticas discursivas. A formação histórica latino-americana seria, basicamente então, o resultado bem sucedido dessa articulação política do sujeito ao fluxo dos discursos praticados nos currículos.

A seleção e circulação de conteúdos relativos à História da América Latina nas práticas curriculares da disciplina ELA, neste contexto, passa a ser um investimento dos 
professores, e da escola como um todo, em reivindicar a construção das memórias possíveis sobre o continente, num entendimento de que apesar das particularidades da história de cada país, de cada região, de cada grupo social, a América Latina partilha uma história comum, que é diferente da dos demais continentes/nações.

A representação que um indivíduo faz de si mesmo, daquilo que memora sobre si e sobre os outros, para si e para os outros, estaria naquela sutura que Hall (2000) sugere no processo de construção identitária - entre aquilo que lhe é oferecido e aquilo pelo qual ele se filia. Trata-se de um currículo que reconhece e assume sua postura política na construção e consolidação de identidades, especialmente a latino-americana.

No entanto é oportuno lembrar que mesmo que o DJ tenha optado pelo modelo quadripartite francês no Ensino de História, sem a referência explícita das identidades que pretende construir, isso não significa que ele seja "neutro”. Em primeiro lugar, como já foi registrado, mesmo não assumindo explicitamente o compromisso com o discurso tradicional açoriano e católico no texto do Projeto Político Pedagógico da escola, as práticas dos docentes deixam claro este partido. Em segundo lugar, ao assumir a tradição eurocêntrica na forma de organização e circulação dos conteúdos históricos existe uma evocação sobre o lugar dos sujeitos e a disponibilidade de memórias sobre si. Entre os conteúdos históricos ensinados no DJ também estão presentes conhecimentos relativos à América Latina, porém em outra perspectiva e intensidade.

O que as análises aqui apresentadas trazem a tona é a medida de conquista da articulação política entre memória e identidade latino-americana no fluxo de dois currículos distintos. Ambos são comprometidos com a construção de memórias coletivas e funcionam como configuradores de sujeitos e identidades. A memória, relacionada aqui com a categoria de identidade, se institucionalizou no ocidente como o campo específico da cultura a que chamamos História. Isso acontece quando o conhecimento sobre o passado, e a nossa relação com ele, ultrapassa os enlaces biográficos e volta-se para cadeias de gerações.

Mas como lembra Maurice Halbwachs (1990), embora sejam os indivíduos os que lembram, no sentido literal da expressão, são os grupos sociais que determinam o que é “memorável” e as formas pelas quais será lembrado. Desta forma os indivíduos terminam por se identificar com os acontecimentos relevantes para o seu grupo. Joël Candau (2011) problematiza os discursos acerca dos argumentos teóricos de construção da memória coletiva, assim como propôs Halbwachs (1990), e elucida melhor as reflexões propostas neste artigo. Candau (2011) diferencia a memória como faculdade humana e a memória como arranjo 
social nos fluxos de políticas de construção de identidades. O autor chama esse arranjo de “representações de metamemória” que, segundo ele,

é a representação que cada indivíduo faz de sua própria memória, o conhecimento que tem dela e, de outro, o que diz dela, dimensões que remetem ao 'modo de afiliação de um individuo e seu passado' e igualmente [...] a construção explicita da identidade (CANDAU, 2011, p. 23).

Discordando parcialmente de Maurice Halbwachs, Candau (2011) argumenta que na suposição de que haja representações comunicáveis entre os atos de memória coletiva, e possíveis de serem transmitidos, não há como afirmar que são compartilhados. Esse arranjo de memória coletiva funciona como regulação da memória individual, por isso nunca concretiza como uma generalização porque as memórias individuais são sempre espraiadas. Segundo o autor:

Maurice Halbwachs se equivocou em ver nas memórias individuais os 'fragmentos' da memória coletiva, conferindo a essa a substancia com a qual tende a despojar as primeiras. Mas teve razão em insistir sobre a importância dos quadros sociais que fazem com que 'uma corrente de pensamento social [...] tão invisível quanto o ar que respiramos' irrigue toda rememoração (CANDAU, 2011, p. 48-49).

As práticas curriculares das duas escolas investigadas estão comprometidas com esses arranjos que Candau (2011) chama de “retóricas holístas”, ou seja, os discursos generalizados que servem como substratos para a composição e organizações sociais dos grupos. No DJ observa-se claramente a opção política pela construção de identidades regionais, a partir daquilo que a História ensinada empresta aos arranjos da memória coletiva, frente a um ensino de História cujo centro tradicionalmente tem sido a Europa.

Nesse sentido, ao analisar as narrativas produzidas no contexto desta pesquisa seria um erro confundi-las com as lembranças individuais dos participantes ou mesmo com um produto definitivo do processo de construção de memórias coletivas sobre a América Latina. A construção de memórias históricas é um processo dinâmico e não se finaliza nas experiências escolares, mas nas palavras de Candau, “[...] para ser útil às estratégias identitárias, ela deve atuar no complexo jogo da reprodução e da intervenção, da restituição e da reconstrução, da fidelidade e da traição, da lembrança e do esquecimento" (CANDAU, 2011, p. 106).

Na esteira do pensamento de Candau, os arranjos que organizam uma "memória coletiva” mais convergente podem estar também nos territórios dos currículos escolares. Ou 
seja, que memória lembrar? Qual esquecer? E com qual finalidade? Jörn Rüsen ${ }^{4}$ aponta que o jogo do lembrar e esquecer fornece as referências temporais que o passado tem de assumir, a fim de poder produzir uma representação de continuidade que possa orientar a construção de horizontes de expectativas. Desta forma, a memória torna o passado significativo, o mantém vivo e o torna uma parte essencial da orientação da vida presente (RÜSEN, 2001, p. 84; 2009 p. 164).

A expectativa representa o futuro-tornado-presente, o horizonte expressa a potencialidade desse desdobramento e superação relacionada à expectativa. Nesta medida, a noção de tempo assume então duas formas distintas, porém mescladas: experiência (tempo natural) e intenção (tempo humano). A primeira é experimentada e interpretada, já a segunda é projetada.

Esta orientação para o futuro da memória passa pela formação de uma “consciência histórica”, numa relação interdependente entre passado-presente-futuro onde a história é interpretada de modo a compreender o presente e perspectivar o futuro (RÜSEN, 2012, p. 70). Em relação à América Latina, significa a capacidade de utilizar a história da América Latina para analisar uma situação presente e determinar um curso de ação.

[...] consciência histórica significa, nesta perspectiva, em última análise, a aprendizagem histórica no nível fundamental e básico do trabalho de memória necessário para a vida prática (RÜSEN, 2012, p. 71).

Para a pragmática deste processo são cruciais os fatores de comunicação da História (RÜSEN, 2012, p. 112), neste caso, o ensino. Vale nessa investigação perceber e problematizar as medidas dos arranjos de construção de memórias e identidades no interior dos currículos escolares.

\section{Os jovens e a América Latina}

A partir das informações obtidas com o survey, identificou-se que a média de idade dos participantes da pesquisa é de 13 anos, a grande maioria residia no município de Florianópolis, em casa própria com os familiares, não trabalhavam e estudavam nas escolas investigadas desde a educação infantil.

\footnotetext{
${ }^{4}$ Embora esse artigo privilegie os Estudos Culturais como referencia epistemológica para as reflexões acerca do problema apresentado, considera-se importante o registro das contribuições sobre os estudos da consciência histórica diante da ampla discussão do tema no campo das pesquisas no Ensino d e História e a inferência da temática nos arranjos da memória.
} 
È necessário explicitar que a escolha pela categoria juventudes não atende a cronologia demarcada pelos órgãos e documentos oficiais. De acordo com a Organização das Nações unidas (ONU) e a Organização Mundial da Saúde (OMS), compreende por jovens no Brasil, as pessoas de 15 e 24 anos, existe ainda a discussão para estender até essa fase até os 30 anos. A definição dessa faixa de idade possui relação com a qualidade e expectativas de vida em um país, é uma categoria sociológica e política que implica na preparação dos indivíduos para o exercício da vida adulta, sua condição como idoso e a garantia de previdência social. A adolescência, para as mesmas instituições, é um processo fundamentalmente biológico, que vai dos 10 aos 19 anos, abrangendo a pré-adolescência (10 aos 14 anos) e a adolescência (15 aos 19). O documento brasileiro que demarca essa fase - o Estatuto da Criança e do Adolescente, ECA - diz que se trata da fase que vai dos 12 aos 18 anos incompletos, sendo o período imediatamente posterior à infância. Entende-se que essas preocupações cronológicas que definem precisamente os limites entre adolescentes e jovens estão no campo das políticas públicas especiais para a preparação para a vida no trabalho, de iniciação a vida sexual saudável, participação política eleitoral, controle de natalidade, entre outros.

Esta pesquisa esteve muito preocupada em entender os jovens a partir das suas relações culturais, dos seus consumos de mídia, das suas vidas na escola. A partir dos resultados da pesquisa surwey esta pesquisa considerou a existência desses enfoques cronológicos dos conceitos, mas preferiu destacar o modo de apresentá-los em um enquadramento não cronológico. Entendeu-se que o “estar” jovem ou adolescente ultrapassa o tempo linear como uma expectativa de chegada - a fase adulta - e expressam possibilidades estéticas de um mercado, exposto especialmente a partir do consumo de mídias. Beatriz Sarlo (1997), ao analisar a pós-modernidade, fala de um “estilo jovem” e historia os sentidos de juventude. Ela fala da juventude do nosso tempo, estendida a um terço da vida. Uma vida com a infância e a velhice diminuídas. Nas suas palavras:

A infância quase desapareceu, encurralada por uma adolescência precocíssima. A primeira juventude se prolonga até depois dos trinta anos. Um terço da vida se desenvolve sob o rótulo de juventude, tão convencional quanto quaisquer outros rótulos. Todo mundo sabe que esses limites, aceitos como indicação precisas, costumam mudar o tempo todo. (SARLO, 1997, p. 36)

A juventude enquanto estilo pronto para ser consumido absorve outros consumos, como o rock, o pop, o jeans, o tênis, um jeito de lidar com a sexualidade, de ser despojado. 
Quando os autores Félix Guattari e Sueli Rolnik (1999) falam sobre a cultura como um conjunto de linguagens, um mercado que absorve e transforma em produtos consumíveis os vários estilos e signos de diferentes tradições, a juventude e tudo que ela agrega é apenas um desses produtos. Esteticamente, tanto os bebês já se vestem cada vez mais com roupas e acessórios do jovem em miniatura (os tênis, os bonés, bermudas, minissaias, jeans, regatas e até fraldas com imitação do tecido jeans), quanto à velhice tem nas cirurgias plásticas, roupas e acessórios um prolongamento da estética juvenil. Talvez o conceito de juventude tenha sido o produto imaterial mais consumido neste mercado cultural do que os autores Guattari e Rolnik (1999) chamam de Capitalismo Mundial Integrado, CMI. E a forma como socialmente essa estética é consumida, considerando classe, etnia, credos, gênero, torna esta experiência plural. E não é possível mais falar em juventude, mas juventudes. Sempre múltiplas. Essa foi a escolha conceitual desse artigo, apesar de tratar de estudantes de 13 anos, estamos os entendendo como jovens, corpos como terminais ou vetores de seus consumos, lócus de marcas, signos, registros que o mercado da juventude disponibiliza, indiferente da idade. Os jovens estudantes das duas escolas se mostraram totalmente aberto aos consumos, às novidades do mundo, corpos que funcionam como um terminal que recebe, seleciona, consome e repele informações, conceitos, estéticas, formas, enfim, produtos materiais e imateriais com um descompromisso autorizado e legitimado pela sua suposta "essência” que lhes conferem os discursos científicos da Medicina, Psicologia, Pedagogia etc.

No geral, os jovens estudantes do CA apresentaram um nível socioeconômico mais alto do que os jovens estudantes do DJ, o que pôde ser verificado pela renda declarada e pelo padrão de consumo. No entanto, o "perfil” do consumo de mídias entre os jovens que participaram da pesquisa parece ser o mesmo: a principal ocupação desses jovens é a música, em primeiro lugar, depois os amigos e o computador em seus vários usos, desde jogar e pesquisar na internet até conversar com amigos através de programas específicos como o MSN. Em seu tempo livre, eles preferem ver televisão a ler literatura. Esse dado é consonante ao perfil de jovens que aparecem em outras pesquisas na América Latina. Jesús MartínBarbero indaga como pesquisador:

Não teríamos, aqui, uma oportunidade para indagar por que os jovens - pela primeira vez na história do Ocidente - encontraram na música seu idioma por excelência, tanto para consumir quanto para criar? E também, não será a música a interface que permite ao jovem se conectar, entre si, referentes culturais e domínios de práticas e saberes que, para os adultos, resultam tão heterogêneos e impossíveis de juntar? (BARBERO, 2008, p. 16) 
É o mesmo autor que também ressalta que o consumo da internet e da televisão não são sinônimos de isolamento da vida social ou ausência da realidade em uma imersão da fantasia virtual. O que as ultimas pesquisas com jovens tem mostrado é que, ainda que essas mídias provoquem dependência nos jovens eles não perderam o habito de sociabilidade (BARBERO, 2008, p. 22-23). Nas duas escolas pesquisadas esses dados se sustentam, depois da música a segunda maior atenção são os amigos. Mesmo que o interesse pelo computador esteja presente os amigos estão do outro lado, no MSN ou em jogos.

A vida familiar desses jovens é bastante significativa e os pais participam consideravelmente da vida escolar dos filhos, seja acompanhando as tarefas de casa, participando das reuniões ou auxiliando no estudo para as provas. Com isso pôde-se concluir que jovens diferentes, em contextos escolares distintos, ocupando espaços diferenciados, especialmente no quesito classe social, apresentaram perfis muito mais semelhantes do que diferentes, nos quais os consumos de mídias, com destaque para a música, ocupam um papel de destaque.

Em relação ao aprendizado de conteúdos históricos relacionados à América Latina, a maioria dos jovens envolvidos na pesquisa no CA declarou que a disciplina ELA foi o meio que mais contribuiu para este aprendizado. No DJ, o percentual daqueles que declararam que a aprendizagem sobre América Latina se deu na disciplina de História se equiparou à importância dada à internet. Em todo caso, junto às disciplinas estiveram outros meios, como filmes, documentários e noticiários, de peso superior nas duas escolas. Esse dado evidenciou que apesar da importância dada ao currículo escolar, seria um grande erro desconsiderar o aprendizado dos jovens a partir das mídias, de forma livre, não mediada, mas reconhecidamente legítima pelos próprios jovens como lócus de aprendizagem. Esse dado se desdobrou na evidencia de que as representações que muitos jovens apresentaram em suas narrativas não foram estudadas nas disciplinas escolares.

Entre os estudantes do CA, 41,8\% deles declararam acreditar que ao estudar a História da América Latina estavam estudando sobre sua própria história. Já no DJ essa clareza foi de 37,8\%. Contudo, as respostas “não” e "talvez” somaram mais do que as respostas "sim” nas duas escolas. Por outro lado, quando questionados sobre a participação das disciplinas para pensar a situação da América Latina na atualidade, 49,3\% dos jovens do CA informaram que a disciplina cursada contribuiu sim para este aspecto, enquanto apenas 15,6\% dos jovens do DJ fizeram esta afirmação. Quando escreveram sobre a América Latina na atualidade, de onde veio o repertório para o texto? Cerca de 50\% do CA e 16\% do DJ afirmaram ser da disciplina, e o restante? Supõe-se que seja a mídia a colaboradora da formação histórica desses jovens. 
Livre de mediação pedagógica ou qualquer regulação interpretativa as identificações vão sendo construídas.

Nas narrativas elaboradas pelos anos do CA sobre o passado, o presente e o futuro da América Latina os elementos mais freqüentes, foram: a ocupação européia violenta e a idéia de aculturação da população nativa; os nomes de povos pré-colombianos; a idéia de que a América Latina é subdesenvolvida ou está em desenvolvimento; a profecia Maia sobre o fim do mundo; o desenvolvimento tecnológico e suas conseqüências; a chegada dos europeus; a chegada do homem à América pelo Estreito de Bering e o desmatamento e a poluição. Muito embora temas como a profecia Maia sobre o fim do mundo, que estava visivelmente fundamentada no filme recém lançado, “2012”, o desenvolvimento tecnológico, desmatamento, o discurso ambientalista, a poluição foram pontualmente marcados pelo conteúdo midiático, a maioria dos jovens do CA tinham repertórios de passados sobre a América Latina.

No DJ as narrativas foram mais limitadas com relação ao passado. Apenas quatro vezes apareceram citações sobre os colonizadores (espanhóis ou portugueses). Essas quatro narrativas destacaram o sentido desrespeitoso com as colônias. E um deles explicou o presente a partir dessas relações no passado. Cinco vezes eles citaram os índios. Essas citações eram generalizadas, sem nome de tribos ou civilizações específicas, apenas uma vez apareceu a referencia nominal aos Maias, no entanto, acredita-se na interferência midiática relacionada ao lançamento do filme "2012”.

Essas questões indicam que de alguma forma a disciplina de ELA, no CA, interferiu no conhecimento desses jovens sobre a América Latina, pois os elementos mais freqüentes nessas narrativas estão diretamente relacionados aos conteúdos ministrados durante o ano letivo de 2009. Cabe destacar que nas últimas semanas anteriores à aplicação do instrumento os jovens estudaram a chegada dos europeus na América Latina na disciplina de ELA. Ou seja, a questão de maior significância entre as narrativas produzidas fez referência direta ao último conteúdo estudado. Nas narrativas a seguir esses traços aparecem bem marcados no texto ${ }^{5}$ :

Tudo começou com os povos que moravam na América Latina chamado os povos Astecas, Incas, Maias e Olmecas, vivendo por vários séculos, até que um dia os espanhóis mataram esses povos para colonizar a América [...] (Narrativa CA A06)

\footnotetext{
${ }^{5}$ Os textos dos estudantes foram digitalizados mantendo a grafia do estudante e seu anonimato. Esta análise não se preocupou com a forma convencional da escrita, mas se importou com os sentidos sobre a América Latina que apareceram nas narrativas.
} 
[...] algumas centenas de anos depois chegaram os europeus que escravisaram e extraíram riquezas daquela terra.

Por causa da extração de riquezas da América Latina os países hoje tem como seu desenvolvimento muito baixo conhecido como subdesenvolvido. (Narrativa CA A05)

Para esses jovens, o processo de colonização da América Latina foi extremamente violento e deixou marcas perceptíveis no presente, seja pela atual situação dos povos indígenas, seja para justificar o subdesenvolvimento do continente. No entanto, afora a real brutalidade desse processo, essas narrativas evidenciam uma visão vitimizada da história da América Latina. "O passado da América foi triste pois seu povo foi massacrado em cima pelos espanhóis e embaixo pelos portugueses. Essa colonização brutal deixou marcas até hoje no presente.” (Narrativa CA B10) Esse olhar que faz dos latino-americanos vítimas de um mundo hostil, tira-lhes a responsabilidade sobre sua história e traz implicações negativas para o horizonte de expectativas e possibilidades de ação desses jovens. A visão da profecia Maia acabou por anunciar um fim para a América Latina, por vezes esse fim apareceu nas narrativas dos jovens de forma apocalíptica, influenciando as expectativas de futuro, como a narrativa a seguir:

\footnotetext{
"Os indios que viviam na América Latina foram torturados e massacrados pelos Espanhóis que se achavam superiores e que o deus deles era melhor que o dos índios, mas hoje no século 21 , os índio estão nas reservas e a América Latina está melhor do que antes, econômia, tecnologia e o desenvolvimento, mas os maias preveram que alguma ruim vai acontecer em 21 de dezembro de 2012 então não sei o que esperar do futuro. (narrativa CA B03)
}

Ou às vezes atravessada também por uma idéia redentora de paraíso, como o exemplo abaixo:

\begin{abstract}
Porém eu vou dizer a MINHA opinião (embora eu não deveria), eu acho que em 2012 o mundo irá acabar, só que não das formas que as pessoas julgam, e sim de uma forma bem diferente, porque para mim em 2012 as "coisas ruins" acabaram e a inocência e a pureza reinaram, portanto para mim em 2012 acontecerá coisas (que não cabe a mim julgar, se são boas ou ruins), em 2012 iniciará uma nova era, uma era de luz, misericordia e paz. (narrativa DJ B12)
\end{abstract}

Em relação às perspectivas de futuro, o pessimismo, envolvendo tanto a profecia maia quanto as catástrofes climáticas, por conta do desmatamento e da poluição, ou o aumento da violência e do desemprego, ou mesmo a idéia de um paraíso configuram um cenário assustador, 
para acionar ações a esses sujeitos juvenis. Esse dado também apareceu nas pesquisas desenvolvidas por Ferreira, Pacievitch e Cerri (2009), utilizando o survey intercultural entre jovens brasileiros, argentinos e uruguaios. A presença desse elemento nas narrativas dos jovens das duas escolas pode estar relacionada ao discurso catastrófico dos meios de comunicação de massa sobre os danos irreversíveis causados ao meio ambiente. Por outro lado, se o futuro é construído pelas escolhas feitas no presente, o que esses jovens estão fazendo para reverter esse quadro? Qual o seu papel enquanto sujeitos desse processo?

Isso mostra que permanece um desafio para a ressignificação do olhar sobre a América Latina. Além disso, mesmo no CA onde os estudos foram mais sistemáticos, para oito jovens a história da América Latina ainda começa com a chegada dos europeus, não apareceu em suas narrativas a presença de povos anteriores aos europeus. E no DJ quando se falou dos povos indígenas, ficou explícito o reconhecimento de um Outro, diferente e sem conexão com a cultura do seu lugar e a ideia de cultura fixa e sem movimento. "Eu sei que a maioria dos povos indígenas continuam com a mesma cultura.” (Narrativa DJ A06) Não existe identificação com esse Outro e o coloca como impermeável, distante da plasticidade do seu próprio mundo, que muda, que se desenvolve e “evolui” progressivamente. A ideia de que o passado foi pior, no presente temos problemas, mas no futuro podemos ser melhores aparecem em grande parte das narrativas e também foi observado por Schmidt e Barca (2009), ao analisarem as narrativas históricas de jovens brasileiros e portugueses sobre a história contemporânea de seus países.

Seja melhor com “a ajuda de Deus”, seja melhor com as ações humanas, mas de alguma forma, as narrativas que não sugeriram o fim do mundo em 2012 desejaram ou apostaram em um futuro melhor. Diante da ideia cristalizada de progresso, afirmar que a cultura dos povos indígenas continua a mesma é o mesmo que se posicionar superior a eles.

E esse progresso e desenvolvimento aparecem, também, com tensões nas narrativas. As questões referentes à tecnologia, desmatamento e poluição estão presentes de forma significante nas narrativas das duas escolas. Em muitos casos a relação entre esses elementos é contraditória, pois enquanto para uns o desenvolvimento tecnológico garante um futuro melhor, para outros agrava os problemas com a poluição e o desmatamento. Isso evidencia um dos aspectos fundamentais desta pesquisa: a produção de narrativas está permeada de contradições do próprio presente e cabe ao pesquisador atento observar a relação entre o que muda e o que permanece quando uma mesma questão é posta de forma diferente.

Também é recorrente entre muitos jovens o sentido de que América Latina é subdesenvolvida ou está em desenvolvimento. Essa ideia pode estar articulada ao lugar que 
ocupam os países latino-americanos na economia mundial já que é comum pensar que o mundo está dividido em países desenvolvidos e países subdesenvolvidos. Os países em desenvolvimento seriam as antigas colônias e países dependentes que tem um desenvolvimento econômico pequeno em comparação com os países altamente industrializados. No entanto quais países podem ser considerados desenvolvidos atualmente? Quais são os critérios que determinam que um país ou continente está em uma ou outra categoria?

Mas o interessante nessas narrativas foi que, de forma equivocada ou não, esses jovens falaram sobre o presente da América Latina usando os conteúdos estudados na disciplina ELA como suporte para suas argumentações. Essa marca apareceu claramente nas narrativas. Já no DJ, como não havia um trabalho sistemático sobre o assunto previsto no currículo, essas questões apareceram espraiadas na disciplina de História, algumas vezes na Geografia ou projetos independentes em uma atividade ou outra na escola,como já foi apresentado. Desta forma, ficou claro o pouco repertório ou, por vezes, ausência completa de informações históricas sobra a América Latina. Em três narrativas a América Latina apareceu como se fosse um país, uma vez como se fosse um continente e três jovens afirmaram que o Brasil não era um país latino. No mais, foi mais comum o aparecimento de informações midiáticas como a violência, desigualdade social, corrupção, conflitos internos e problemas ambientais e capacidade de crescimento econômico. Da mesma forma, a referencia ao futebol apareceu por três vezes, a rivalidade entre Brasil e Argentina também apareceu três vezes, mas sem relação direta com o futebol e as referências aos astros de TV apareceram duas vezes.

Algo muito especial foi observado em algumas narrativas nas duas escolas: o ponto referencial com os EUA. As narrativas dos jovens do DJ, ao mesmo tempo em que mostraram pouca informação sobre a América Latina, tanto de passado quanto de presente, se colocaram como inferiores a América Anglo Saxônica. Referenciaram os EUA como lugar superior, um modelo a ser espelhado, um desejo de ser igual, uma representação de desenvolvimento de organização social. Essa comparação apareceu em narrativas como a seguir:

O passado da América Latina, colonizado por espanhóis, com escravização. O Brasil foi o último país a deixar a escravidão. Levaram as riquezas para a Espanha. Enfim, foram escravizadas, colonizadas. Tem seus motivos para serem “inferiores” aos Estados Unidos.

O presente da América Latina. Hoje vejo muita violência, estupros, mortes por besteiras. Claro que eu vivo coisas boas, tenho uma família legal, passeio, consigo ver o lado bom da vida. Mas hoje em dia as pessoas tem medo de sair a noite sozinha e muitos outros aspectos. 
O futuro da América Latina. Se continuar como está, a gente não vai conseguir sair de casa, mas temos que ter esperanças e acreditar que o futuro pode ser bom, podemos acabar com a violência. Mas o futuro a Deus pertence então vejamos o que vai dar.

Gosto da América Latina, mesmo com seus defeitos, afinal ninguém é perfeito. (Narrativa DJ A01)

A narrativa inicia reconhecendo um passado de colonização com problemas e justifica o presente a partir desse passado, “Tem seus motivos para serem "inferiores" aos Estados Unidos”. Além de entender que a colonização foi um fator determinante para o presente, esse jovem destaca os EUA como referência comparativa. E quando fala em futuro relaciona com a esperança em Deus. Essa crença possui relação com o currículo do DJ. Como anunciado anteriormente, não existe evidencia no texto do PPP da escola esse compromisso com a religião, no entanto, estão nos cartazes espalhados pela escola, no envolvimento com a agenda da paróquia, na fala da equipe de professores. Esse sentido aparece na expectativa de futuro explicitado nessa narrativa. Quando esse jovem faz esse movimento no texto ao mesmo tempo em que “entrega pra Deus” também diz "podemos acabar com a violência”. Ao dizer isso mostra que acredita ter sujeitos nessa História, e se reconhece como diferencial no meio de tantos problemas quando diz "eu vivo coisas boas” e se refere a família.

Outro exemplo de comparações com os EUA e de expectativas de futuro está em outra narrativa que segue. Ao descrever uma América Latina no futuro o texto diz:

Descreveria ela com um lugar massa, eu bem longe daqui, mais espero que seja um lugar cheio de pessoas famosas tipo Holiudi, cheio de lugares badalados e chiques.

E para o meu futuro - eu espero, viver em Nova York, sendo alguém famosa, e cheia de amor e carinho para dar e vender, para poder ajudar as pessoas carentes. (Narrativa DJ A21)

Um texto recortado de representações e conteúdos da mídia. O jovem espera que a América Latina esteja bem, mas esse bem é comparado com EUA. Interessante como essa jovem deseja um futuro relacionado à sua representação de estar bem, a partir daquilo que ela imagina ser um lugar perfeito “cheio de pessoas famosas tipo Holiudi”. No entanto, ela "bem longe daqui”, porque quer estar em Nova York no futuro. Outra característica interessante no texto é perceber o caminho de sucesso na fama com o fim de ajudar as pessoas carentes. Uma manifestação de expectativas de futuro construída em programas de auditório? Não se pode ter certeza disso, no entanto, as narrativas nos dão pistas de que, diante da ausência de repertório sobre o passado, os jovens apreendem com a mídia as representações sobre a 
América Latina, recortadas apenas em problemas e se identificam com aquilo que imaginam ser os EUA.

Os problemas contemporâneos da América Latina aparecem bastante nas narrativas dos jovens das duas escolas, entre eles, os que mais se destacaram foram tensões relacionadas ao Gasoduto, ASFARC e o narcotráfico e Hugo Chaves na Venezuela como ameaça. Especialmente nas narrativas do DJ existe claramente uma memória pejorativa sendo construída. Já nas narrativas do CA, embora esse tom pejorativo às vezes apareça, existem conteúdos históricos sobre um passado que direcionam outras possibilidades para as narrativas.

No DJ apenas uma narrativa questionou o sentido de inferioridade que se constrói sobre o "ser latino-americano": "Hoje em dia, você diz que é americano e as pessoas não reconhecem. Americano é o estadunidense, o brasileiro não é americano, é latino.” (Narrativa DJ A05) O jovem diz não existir a possibilidade de ser reconhecido como americano porque essa nomenclatura é legitimada para o estadunidense, no entanto, resta ao brasileiro ser latino. Apesar de ser uma crítica, ela vem afirmando a inferioridade dessa identidade, como se fosse uma sina. O lugar que se deseja como identificação não possui reconhecimentos pelos outros no jogo de identidade e alteridade. Se ele disser que é “americano” não será reconhecido no lugar que gostaria, mas será interpretado como um erro de linguagem. A identidade precisa do reconhecimento dos outros, ela não se processa apenas na identificação dos sujeitos, mas, mas o essa identificação precisa jogar com aquilo que Hall chama de "marcação de fronteira simbólica” (HAAL, 2000, p. 106)

Não se identificar com o lugar de posição de sujeito que é mapeado nos discursos midiáticos sobre a América Latina pode ser mais simples do que se identificar com aquilo que se acha ser a representação do "ser americano”. A identificação por si apenas não garante o reconhecimento e o pertencimento a um grupo. A identificação “obedece à lógica do maisque-um” (HALL, 2000, p. 106) e isso é um complicador para esse jovem.

Dentre as narrativas do CA também apareceram aqueles que sentiram necessidade de comparação com os EUA, no entanto o sentido foi contrário. O jovem escreveu: "Hoje a América Latina, pelo menos o Brasil está se desenvolvendo muito, cada vez mais em comparação com os outros países, por exemplo EUA.” (Narrativa CA A08). A necessidade de registrar que o Brasil está se desenvolvendo mais que os EUA têm uma razão de ser. Esse jovem poderia ter comparado o Brasil com outros países da própria América Latina, mas os EUA foram a referência. Outro jovem escreveu também: “Falar do presente é bem complicado. Talvez o correto seria falar da bolsa de valores, do dolar ou do presidente do dos 
EUA, mas pra que? Isso pouco interessa a uma adolescente de 14 anos. Vou falar de gente, sentimentos, direitos...” (Narrativa DJ A16). Embora se reconheça que a moeda americana, o presidente dos EUA seja algo importante para o presente, isso pouco importa para esse jovem. Ele quer falar do eu presente, dos seus sentimentos e direitos. Observa-se nas narrativas do CA um posicionamento frente às representações de superioridade dos estadunidenses em relação aos latinos. Seria um efeito do reconhecimento de um passado histórico possível de se identificar?

\section{Reflexões sempre provisórias}

Nos últimos seis anos temos direcionado algumas inquietações para os jovens e suas relações com o Ensino da História sem perder de vista o traço marcante do consumo de mídias e as implicações contemporâneas que esse dado nos aponta. Essas análises especialmente mostraram o investimento de duas escolas, dois grupos de professores diferentes, comprometidos em construir possibilidades de escolhas identitárias para os jovens estudantes. Nas duas situações esses currículos oferecem “retóricas holístas”, parafraseando Candau, ou memórias e identidades supostamente compartilhadas por um grande grupo. No caso do CA uma possível memória latino-americana e no caso do DJ uma possível memória açoriana e cristã. Essa pesquisa possuía como recorte apenas o Ensino da História da América Latina - assunto previsto nos Parâmetros Curriculares Nacionais - e não se ateve a possibilidade de trabalhos mais sistemáticos sobre a "açorianidade”.

Todavia, concordamos com Candau quando ele diz parecer ser abusivo "utilizar as expressões 'identidade cultural' ou 'identidade coletiva' para designar um suposto estado de um grupo inteiro quando apenas uma maioria dos membros desse grupo compartilha o estado considerado” (CANDAU, 2011, p. 26). Isso se torna mais abusivo, como observado nos dois currículos, quando a memória e identidade proposta não pertence a maioria do grupo. Avaliamos que se trata de uma necessidade dos adultos mais experientes do grupo, profissionais da educação, que decidiram as posições de sujeitos que seriam melhor apresentadas aos jovens. Todos os currículos decidem essas posições, que quase sempre são arbitrárias, e fazem parte da necessidade cultural de manutenção dos mais velhos no grupo. São posturas políticas de construção de identidades.

Por um lado, os jovens consomem os currículos construídos para eles, mediados por profissionais que pensaram seus futuros e, por outro lado, consomem diferentes mídias por vezes sem mediação de adultos. Se a análise de funcionamento dos currículos como 
produtores de identidades pode parecer muito orquestrado ou determinista nas escolhas dos sujeitos, os pontos de sutura pelo qual nos fala Stuar Hall, nos fala da complexidade do currículo em fluxo. As analises das narrativas mostraram essa complexidade. Embora as narrativas do CA mostraram maior capacidade de repertório sobre a América Latina - e sabemos que nesse repertório repousa uma convocação de lugares de sujeito para esses jovens se identificarem -, esse investimento não garante o investimento dos jovens nessa identificação. Não temos como saber se a convocação para a escolha dos discursos de açorianidade local infere sentidos de filiação nos jovens do DJ, mas, sobre a América Latina ficou claro que repelem o pouco que sabem sobre ela através da mídia. Identificamos claramente um jogo de “chamamento" e “interpelação” desses jovens nos fluxos dos currículos das escolas em relação com seus consumos midiáticos.

Alguns pontos merecem uma reflexão mais aprofundada. As representações de si dos jovens no DJ pareceu preocupante quando suas narrativas foram constatações de que pertencem a um lugar menor, com corrupção, violência, desigualdades sociais e poucas referências positivas para se orgulharem. Além dessa inferioridade existem comparações com o Outro melhor que é os EUA. Sua localização temporal desenha uma perspectiva de futuro de melhora muito grande, de esperança que tudo vai ficar bem, crêem na tecnologia, na modernidade, mas por vezes condiciona essa melhora a Deus. Esse dado fala sobre uma subjetividade cristã, como o paraíso possível no futuro, e exatamente da 'sutura', do local de 'interpelação’, de intersecção entre aquilo que o currículo propôs (junto com a família, com a igreja e outros consumos) e o investimento dos jovens para sua identidade. São as suas próprias histórias que estão em construção.

Essas análises direcionaram alguns vôos para outras pesquisas que estão em andamento e são sempre provisórias. Apontam para estudos sobre políticas de cultura e políticas de educação para os jovens e sobre a necessidade de considerar o protagonismo juvenil no fazer da sua própria História, das suas escolhas e de suas tessituras identitárias.

\section{Referências}

BARBERO, Jesús-Martin. A mudança na percepção da juventude: socibilidades, tecnicidades e subjetividades entre os jovens. In: BORELLI, Silvia H. S; FILHO, João Freire (Org.). Culturas Juvenis no século XXI. São Paulo: EDUC, 2008.

BRASIL. Secretaria de Educação Fundamental. Parâmetros Curriculares Nacionais: História. Brasília: MEC, 1998. 
CANDAU, Joël. Memória e Identidade. São Paulo: Contexto, 2011.

CONCEIÇÃO, Juliana Pirola; DIAS, Maria de Fátima Sabino. Ensino de História e consciência histórica latino-americana. Revista Brasileira de História. v. 31, pp. 173-191, 2011.

GUATTARI, Fèlix. ROLNIK, Sueli. Micropolítica. Cartografias do desejo. 5. ed. Petrópolis: Vozes, 1999.

HALBWACHS, Maurice. A Memória Coletiva. São Paulo: Vertice, 1990.

HALL, Stuart. Quem precisa de identidade? In: SILVA, Tomaz Tadeu da (Org.). Identidade e Diferença: a perspectiva dos estudos culturais. Petrópolis:Vozes, pp. 103-133, 2000.

LACLAU, Ernesto. Universalism, Particularism and the Question of Identity. October, v. 61, pp. 83-90, verão 1992.

RÜSEN, Jörn. Aprendizagem histórica: fundamentos e paradigmas.Curitiba: W. A. Editores, 2012.

RÜSEN, Jörn. Como dar sentido ao passado: questões relevantes de meta-história. Revista História da Historiografia, n. 2, março 2009.

RÜSEN, Jörn. Razão Histórica - Teoria da História I: Os fundamentos da ciência histórica. Brasília: EDUnB, 2001.

SANTA CATARINA, Universidade Federal de Santa Catarina. Projeto Político Pedagógico do Colégio de Aplicação da UFSC. Florianópolis: UFSC, 2003.

SARLO, Beatriz. Cenas da Vida Pós-moderna. Intelectuais, Artes eL vídeocultura na Argentina. Rio de Janeiro: UFRJ, 1997.

SILVA, Tomaz Tadeu da. A produção social da identidade e da diferença. In: (Org.). Identidade e Diferença: a perspectiva dos estudos culturais. Petrópolis:Vozes, pp 73-102, 2000.

SCHMIDT, Maria Auxiliadora Moreira dos Santos; BARCA, Isabel. Consciência histórica: um diálogo entre países. In: VII Encontro Nacional Perspectivas do Ensino de História, 7, 2009, UFU. Anais. Uberlândia, 2009. 